\title{
Pengukuran Kinerja Perbankan Syariah Berbasis Maqashid Syariah Index Bank Syariah di Indonesia : Abdul Majid Najjar Versus Abu Zahrah
}

\author{
Rudi Setiyobono ${ }^{1}$, Nurmala Ahmar², Darmansyah ${ }^{3}$ \\ 1,3 Universitas Pancasila, Jakarta, Indonesia \\ 2 Sekolah Tinggi Ilmu Ekonomi (STIE) Perbanas, Surabaya, Indonesia
}

\section{INFO ARTIKEL \\ JEL Classification : \\ M41, Z12}

Keywords :

performances of islamic bank $(i B)$, maqashid sharia index

\begin{abstract}
This study aims to analyze the performance of Islamic Banking $(i B)$ in Indonesia through the maqashid shariah index approach. Performance appraisal on Islamic Banking (iB) is generally done through financial performance measurements without including non-financial performance measurements. This study measures the performance of Islamic Banking (iB) through a broader approach to sharia principles by using the concept of maqashid shariah index proposed by Abu Zahrah and Abdul Majid Najjar. This type of research is quantitative descriptive. The object of the research conducted is Bank Umum Syariah (BUS) that operate nationally in Indonesia and are registered with Otoritas Jasa Keuangan (OJK). The type of data used is secondary data in the form of financial reports and annual reports obtained from the official websites of each bank Period 2014 to 2018. By using the maqashid shariah index and the SAW (Simple Additive Weigting) method, it can be concluded that the performance value of MSI of Bank Muamalat Syariah Indonesia (BSMI) in 2014-2018 approach to the concept of Abu Zahrah on average was $35.64 \%$, while the performance value of MSI of BMSI in the same periode with the AM Najjar concept approach the average is $30.56 \%$.
\end{abstract}

\begin{abstract}
ABSTRAK
Penelitian ini bertujuan untuk menganalisis kinerja Perbankan Syariah (iB) di Indonesia melalui pendekatan maqashid shariah index. Penilaian kinerja Perbankan Syariah (iB) umumnya dilakukan melalui pengukuran kinerja secara keuangan tanpa mengikutsertakan pengukuran kinerja non keuangan. Penelitian ini mengukur kinerja Perbankan Syariah (iB) melalui pendekatan prinsip-prinsip syariah secara lebih luas dengan menggunakan konsep maqashid shariah index yang dikemukakan oleh Abu Zahrah dan Abdul Majid Najjar.Jenis penelitian yang digunakan adalah deskriptif kuantitatif. Objek dari penelitian yang dilakukan adalah bank umum syariah (BUS) yang beroperasi secara nasional di Indonesia dan terdaftar pada otoritas jasa keuangan (OJK. Jenis data yang digunakan adalah data sekunder berupa laporan keuangan dan laporan tahunan dari situs resmi masing masing bank Periode tahun 2014 sampai 2018. Dengan menggunakan maqashid shariah index dan metode SAW (Simple Additive Weigting),
\end{abstract}


dapat disimpulkan bahwanilai Kinerja MSI Bank Muamalat Syariah Indonesia (BMSI) tahun 2014-2018 pendekatan konsep Abu Zahrah rata-rata adalah sebesar 35.64\%. Sedangkan nilai kinerja MSI periode yang sama dengan pendekatan konsep AM Najjar rata-rata adalah sebesar $30.56 \%$.

\section{Pendahuluan}

Tuntutan untuk melaksanakan kegiatan operasional berdasarkan prinsip syariah pada institusi islami telah membuat banyak usaha yang dilakukan untuk mengevaluasi kinerja sesuai dengan prinsip syariah. Pada penelitian yang dilakukan di Malaysia yang meneliti tentang pengungkapan alternatif dan peninjauan terhadap kinerja untuk Bank Islam. (Hameed, Wirman, \& Nazli, 2004) salah satu indikator penilaian yang digunakan untuk mengevaluasi kinerja yang didasarkan prinsip syariah islam adalah menggunakan Islamicity Performance Index (IPI). Menurut AAOIFI Islamicity Performance Index (IPI) terdiri dari tujuh komponen, antara-lain: profit sharing financing ratio, zakat performance ratio, equitable distribution ratio, directors- employees welfare ratio, islamic invesment vs non-islamic invesment, Islamic income vs non-islamic income.Walaupun alternatif penilaian diatas sudah diukur dari beberapa dimensi sesuai prinsip Islam, namun penilaian tersebut belum secara komprehensif bisa mewakili tujuan syariah (maqashid syariah) untuk bank syariah. Model pengukuran kinerja syariah islami yang digunakan untuk mengukur kinerja lembaga syariah adalah menggunakan pengukuran kinerja maqashid syariah

Pengukuran indikator kinerja maqahid syariah tidak hanya mengungkapkan indikator kinerja keuangan yang disajikan dalam laporan keuangan berdasarkan prinsip-prinsip akutansi sebagai tolok ukur namun juga mencoba mengungkapkan indikator kinerja non keuangan. Pentingnya pengungkapan kinerja non keuangan dalam mengukur kinerja lembaga syariah adalah sejalan dengan prinsip-prinsip ekonomi syariah dan lembaga syariah.Triyuwono(2012:355)

mengungkapkan akuntansi syariah tidak saja sebagai bentuk akuntabilitas (accountability) manajemen terhadap pemilik perusahaan (stockholders), tetapi juga sebagai akuntabilitas kepada stakeholders dan Tuhan. Syaria Enterprise theory mengandung nilai keadilan, kebenaran, kejujuran, amanah, dan pertanggung jawaban, bentuk pertanggung jawaban utamanya kepada Allah SWT.

Magashid syariah index merupakan sebuah alternative model pengukuran kinerja bagi perbankan syariah yang pada umumnya menggunakan rasio profitablitas semacam ROA, ROE atau ROI sebagai alat kinerja keuangan. Penilaian kinerja perbankan syariah masa kini cenderung memprioritaskan aspek pencapaian laba (ekonomi), dan terkadang melupakan prioritasnya dalam memenuhi fungsi sosial (maslahah) nya. Penilaian kinerja pada perbankan konvensional maupun syariah biasanya hanya melihat pengukuran kinerja keuangan dengan menggunakan rasio CAMELS (Capital, Asset, Management, Earning, Liquidity, Sensivity of Market Risk) dan EVA (Economic Value Added) (Antonio et al. 2012).

Penelitian ini menawarkan 2 model pengukuran lain bagi kinerja perbankan syariah yaitu maqashid syariah index. Penelitian tentang kinerja maqashid syariah selama ini pada umumnya menggunakan konsep maqashid syariah menurut $\mathrm{Abu}$ Zahrah yang dikembangkan oleh Mohammed and Taib (2015), dan konsep maqashid syariah index (MSI) AM Najjar yang dikembangkan oleh Bedoui (2016). Konsep pengukuran kinerja maqashid syariah $\mathrm{Abu}$ Zahrah membagi maqashid syariah menjadi 3 tujuan utama, yaitu: (1). Tahdzib al fard (Pendidikan individu), (2). Iqamah al-adl (Menegakkan keadilan), (3). Jalb al maslahah dan masing- masing tujuan seluruhnya terdiri dari 10 elemen yang diukur menggunakan rasio dan bobot yang telah ditentukan. Indikator kinerja maqashid syariah Abu Zahrah terlhat pada Tabel 1.1. berikut: 
Tabel 1.1. Maqashid Syariah Abu Zahrah

\begin{tabular}{|c|c|c|}
\hline No & Tujuan Pokok & Elemen \\
\hline \multirow{4}{*}{1} & \multirow{4}{*}{$\begin{array}{l}\text { Tahzib El Fadr (Educating } \\
\text { Individual/Pendidikan } \\
\text { Individu) }\end{array}$} & E1. Education Grand (Hibah Pendidikan) \\
\hline & & E2. Research (Penelitian ) \\
\hline & & E3. Training (Pelatihan) \\
\hline & & E4. Publicity (Publikasi) \\
\hline \multirow{3}{*}{2} & \multirow{3}{*}{$\begin{array}{l}\text { Iqamah al-Adl (Establishing } \\
\text { of Justice/Menciptakan } \\
\text { Keadilan) }\end{array}$} & E5. Fair Returns (Pemngembalian yang Adil) \\
\hline & & E6. Functional Distribution (Distribusi Fungsional) \\
\hline & & E7. Interest free Product (Produk bebas bunga) \\
\hline \multirow{3}{*}{3} & \multirow{3}{*}{$\begin{array}{l}\text { Jalb al-Maslaha (Public } \\
\text { Interest/Kepentingan Umum) }\end{array}$} & E8. Profit ratios (Profit rasio) \\
\hline & & E9. Personal Income (Pendapatan personal) \\
\hline & & E10. Investment Ratios in Real Sector (Investasi pada Sektor Riil) \\
\hline
\end{tabular}

Pendekatan lain dalam pengukuran kinerja maqashid syariah adalah menggunakan konsep maqashid syariah index AM Najjar yang dikembangkan Bedoui (2016).Konsep maqashid syariah AM Najjar membagi maqashid syariah menjadi 4 tujuan utama, yaitu: (1). Mengamankan Nilai Kehidupan Manusia, (2). Mengamankan Diri Manusia, (3).Mengamankan Masyarakat, dan (4).Mengamankan lingkungan, dan kemudian membagi keempat pokok tersebut kedalam 8 elemen.Pengukuran maqashid syariah index konsep AM Najjar dinilai lebih bersifat komprehensif, dan lebih lengkap serta menyeluruh karena memasukan juga alat analisa lain seperti islamicity disclosure, dan metode analisis kesehatan CAMELS dalam rangka memperoleh nilai kinerja maqashid syariah index (MSI) perbankan syariah BEDOUI,2012). Konsep maqashid syariah AM Najjar terlihat pada tabel 1.2 berikut:

Tabel 1.2. Maqashid Syariah AM Najjar

\begin{tabular}{|c|c|c|}
\hline No & Tujuan Pokok & Elemen \\
\hline \multirow{2}{*}{1} & \multirow{2}{*}{$\begin{array}{l}\text { Mengamankan Nilai Kehidupan } \\
\text { Manusia }\end{array}$} & E1. Iman (Faith/يعان) \\
\hline & & E2. Hak Azasi Manusia (Human rights/حقأون الأسان) \\
\hline \multirow{2}{*}{2} & \multirow{2}{*}{ Mengamankan Diri Manusia } & E3. Diri Sendiri (Self/(نفش) \\
\hline & & E4. Kecerdasan (Intelligence/sısi) \\
\hline \multirow{2}{*}{3} & \multirow{2}{*}{ Mengamankan Masyarakat } & E5. Keturunan (Descendant/تنازلي) \\
\hline & & E6. Entitas Sosial (Social Entity/الكبان الاجتماعب) \\
\hline \multirow{2}{*}{4} & \multirow{2}{*}{ Mengamankan Linkungan } & E7. Harta (property/da) \\
\hline & & E8. Lingkungan Hidup (Ecology/طلم البينة) \\
\hline
\end{tabular}

Sumber: Bedoui (2012)

\section{Telaah Teori}

\section{Shariah Enterprise Theory (SET)}

Perbankan syariah mempunyai tujuan yang sesuai dan sejalan dengan prinsip-prinsip Islam, yaitu sesuai Al-Quran dan Al-Hadist.
Sebagai badan usaha dalam kategori profit oriented, tujuan perbankan syariah adalah untuk mendapatkan keuntungan sebagian kegiatan operasionalnya. Perbankan konvensional salah satu cara mendapatkan keuntungan lewat pendapatan bunga, dimana di dalam ajaran Islam bunga adalah termasuk katagori riba yang terlarang. Islam telah jelas melarang umatnya untuk mengambil riba, hal ini sangat jelas disebutkan bahwa Allah SWT melarang riba dan menghalalkan jual beli, sebagaimana firmanNya dalam Al-Quran yang berbunyi :

"Dan Allah telah menghalalkan jual beli dan mengharamkan riba." [Al-Baqarah: 275].

Islam secara tegas melarang umatnya untuk mengambil harta milik orang lain dengan jalan yang bathil kecuali dengan jalan perniagaan yang didasarkan atas kesepakatan (akad) dan ridho kedua pihak. Hal ini sangat jelas disebutkan Allah SWT dalam firmanNya yang berbunyi :

"Hai orang-orang yang beriman, janganlah kamu saling memakan harta sesamamu dengan jalan yang bathil, kecuali dengan jalan perniagaan yang berlaku dengan suka sama suka di antara kamu." [An-Nisaa': 29)]

Kekayaan atau disebut maal pada hakekatnya hanyalah titipan dan berkewajiban untuk menafkahkan sebagian daripadanya sesuai keinginan Allah SWT. Hal ini telah dijelaskan dalam Al Qur'an sebagai berikut :

"Berimanlah kamu kepada Allah dan rasulNya dan nafkahkanlah sebagian dari hartamu yang Allah telah menjadikan kamu menguasainya. Maka orang-orang yang beriman di antara kamu dan menafkahkan (sebagian) dari hartanya memperoleh pahala yang besar" (QS. Al-Hadiid, ayat 7)"

Tafsir ayat tersebut dengan tegas menyatakan bahwa harta hakikatnya adalah milik Allah SWT. Manusia hanya dititipkan kekayaan berupa harta yang merupakan milik Allah (spiritual-substantif) dengan segala tanggung jawabnya itu maka manusia diwajibkan untuk menafkahkan sebagian saja dari hartanya dan haruslah sesuai ketentuan Allah (materialitas-syari'ah) agar mendapat ketenangan dan pahala (batin). Maka yang berlaku dalam shari'ah enterprise theory adalah Allah SWT sebagai sumber amanah 
utama, karena Dia adalah pemilik yang tunggal dan mutlak. Begitu pula segala bentuk sumberdaya yang dimiliki oleh para stakeholders pada prinsipnya hanyalah amanah dari Allah SWT yang didalamnya melekat tanggung jawab untuk menafkahkannya dengan cara dan tujuan yang ditetapkan oleh Pemberi Amanah (lihat QS. 2:267) (Triyuwono, 2001):

"Wahai orang-orang yang beriman! Infakkanlah sebagian dari hasil usahamu yang baik-baik dan sebagian dari apa yang Kami keluarkan dari bumi untukmu.Janganlah kamu memilih yang buruk untuk kamu keluarkan, padahal kamu sendiri tidak mau mengambilnya melainkan dengan memicingkan mata (enggan) terhadapnya. Dan ketahuilah bahwa Allah Mahakaya, Maha Terpuji. (QS. Al-Baqarah, ayat 267)"

Implementasi syariah enterprise theory (SET) dimana perbankan syariah dalam kegiatan operasionalnya harus berlandaskan kepada prinsip-prinsip syariah karena perbankan syariah memiliki tanggung jawab tidak hanya bertanggung jawab kepada para pemilik perusahaan semata melainkan juga kepada stakeholder dan Allah SWT.Penerapan prinsip syariah enterprise theory (SET) pada perbankan syariah akan membuat kinerja bank lebih sehat, dikarenakan manajemen senantiasa akan mematuhi prinsip-prinsip yang telah ditetapkan.

\section{Resource Based Value Theory}

Resource Based Value Theory adalah teori yang menjelaskan bahwa perusahaan dapat meningkatkan keunggulannya dalam persaingan dengan cara mengembangkan sumberdaya sehingga mampu mengarahkan perusahaan untuk bertahan secara jangka panjang. Kunci dari pendekatan teori ini adalah pada strategi memahami hubungan antara sumber daya, kapabilitas, keunggulan bersaing, dan profitabilitas khususnya dapat memahami mekanisme dengan mempertahankan keunggulan bersaing dari waktu ke waktu. dalam karyanya yang berjudul "A Resource-based view of the firm". Namun penelitian yang banyak menjadi rujukan adalah artikel karya Barney (1991) "Firm Resource and Sustained Competitive Advantage".Dijelaskan bahwa firm resource dapat membantu perusahaan meningkatkan efisiensi dan efektivitas operasi perusahaan.
Selanjutnya keunggulan kompetitif bersaing dapat dipahami dengan menanamkan pemahaman bahwa perusahaan terdiri dari elemen yang heterogen dan tak bergerak. Langkah untuk memaksimalkan keunggulan kompetitif bersaing, perusahaan harus memenuhi empat kriteria, yaitu valuable, rareness, inimitability dan nonsubstitutability.

\section{Prinsip Kerja Perbankan Syariah}

Sesuai Undang Undang No. 21 tahun 2008 tentang Perbankan Syariah, Prinsipnya bahwa Bank Syariah adalah bank yang menjalankan kegiatan usaha berdasarkan kepada prinsip syariah, atau prinsip hukum islam yang diatur dalam fatwa Majelis Ulama Indonesia. Prinsip kerja Bank Syariah adalah prinsip keadilan, keseimbangan ('adl wa tawazun), kemaslahatan (maslahah), universalisme (alamiyah), serta didalam transaksinya tidak mengandung unsur gharar (ketidak-pastian), maysir atau qimar secara harfiah bermakna judi (spekulasi), riba ziyadah (tambahan), zalim (melanggar hak orang lain) dan obyek yang haram. Sebagaimana Allah SWT dalam firmanNya melarang Riba :

"Wahai orang-orang yang beriman! Janganlah kamu memakan riba dengan berlipat ganda dan bertakwalah kepada Allah agar kamu beruntung, " ( Q.S. Ali Imran [3] : 130).

Mengenai tugas dan fungsi perbankan syariah dalam Undang Undang No. 21 tahun 2008 tentang Perbankan Syariah mengamanahkan bank syariah untuk menjalankan fungsi sosial (maslahah) dengan menjalankan fungsi seperti lembaga baitul maal, yaitu menerima dana yang berasal dari zakat, infaq, sedekah, hibah, atau dana sosial lainnya (membelanjakan harta dijalan Allah SWT) dan menyalurkannya kepada pengelola wakaf (nazhir) sesuai kehendak pemberi wakaf (wakif). Rasulullah SAW bersabda :

"Bukankah Allah telah membukakan bagi kalian pintu-pintu sedekah? Sejatinya setiap ucapan tasbih bernilai sedekah bagi kalian, demikian juga halnya dengan ucapan takbir, tahmid, dan tahlil. Sebagaimana memerintahkan kebajikan dan melarang kemungkaran juga bernilai sedekah bagi kalian. Sampai pun melampiaskan syahwat 


\section{kemaluan kalian pun $\quad$ bernilai sedekah.”. (HR. Muslim).}

Dalam hal pelaksanaan fungsi pengaturan dan pengawasan perbankan syariah dari aspek pelaksanaan prinsip kehati-hatian dan tata kelola yang baik dilaksanakan oleh Otoritas Jasa Keuangan (OJK) sebagaimana halnya yang sama diberlakukan pada perbankan konvensional, namun dengan pengaturan dan sistem pengawasan yang disesuiakan dengan kekhasan sistem operasional perbankan syariah. Sistem dan mekanisme untuk menjamin pemenuhan kepatuhan syariah yang menjadi isu penting dalam pengaturan bank syariah.

Dalam kaitan ini lembaga yang memiliki peran penting adalah Dewan Syariah Nasional (DSN) MUI. Undang-undang No. 21 Tahun 2008 tentang Perbankan Syariah memberikan kewenangan kepada MUI yang fungsinya dijalankan oleh organ khususnya yaitu DSNMUI untuk menerbitkan fatwa kesesuaian syariah suatu produk bank. Kemudian Peraturan Bank Indonesia (sekarang POJK) menegaskan bahwa seluruh produk perbankan syariah hanya boleh ditawarkan kepada masyarakat setelah bank mendapat fatwa dari DSN-MUI dan memperoleh ijin dari OJK. Pada tataran operasional pada setiap bank syariah juga diwajibkan memiliki Dewan Pengawas Syariah (DPS) yang fungsinya ada dua, pertama fungsi pengawasan syariah dan kedua fungsi advisory (penasehat).

\section{Maqashid Syariah}

Maqashid al-Syariah terdiri atas dua kata yaitu kata maqashid dan kata al-syari'ah yang berhubungan antara satu dengan lainnya dalam bentuk mudhaf dan mudhafunilaih. Kata maqshid adalah bentuk jamak dari kata maqshad yang artinya adalah maksud dan tujuan. Kata Syariah yang artinya hukum Allah, baik yang merupakan ketetapan Allah SWT, maupun ditetapkan Nabi sebagai penjelasan atas ketetapan hukum yang ditetapkan Allah SWT atau merupakan ijtihad yang dihasilkan oleh mujtahid berdasarkan apa yang telah ditetapkan Allah atau dijelaskan oleh Nabi. Karena yang dihubungkan kepada kata syari'at adalah kata "maksud atau tujuan", maka kata syari'ah berarti pembuat hukum atau syar'i, bukan hukum itu sendiri. Dengan demikian, kata maqashid al-syari'ah berarti apa yang dimaksud oleh Allah dalam menetapkan hukum, apa yang dituju Allah dalam menetapkan hukum atau apa maksud dan tujuan yang ingin di capai oleh Allah dalam menetapkan suatu hukum.

Implementasi Maqasid Syaria'ah yang ditujukkan melalui penerapan hukum-hukum Islam yang ditetapkan berdasarkan nash-nash agama adalah maslahah hakiki. Maslahah ini mengacu terhadap pemeliharaan terhadap lima hal: (1). Memelihara Agama (al-Muhafazhah ala al-Diin) (2). Memelihara Jiwa (alMuhafazhah ala an-Nafs), (3).Memelihara Akal (al-Muhafadzah ala al-'Aql), (4). Memelihara Keturunan (al-Muhafadzah ala an-Nasl), dan (5).Memelihara Harta (alMuhafadzah ala al-Mal). Kehidupan dunia ditegakkan atas lima pilar tersebut, tanpa terpeliharanya kelima hal ini, maka tidak akan tercapai suatu kehidupan manusia yang luhur secara sempurna. Sebagian ulama diantaranya Imam Syihabuddin Al-Qarafi (w.1285 M./684H.) menambahkan satu kebutuhan lagi yaitu, pemeliharaan kehormatan (hifdzi al Irfd). Sehingga dengan kata lain, tujuan puncak ajaran Islam bisa dinamakan tujuan-tujuan primer (AlMaqashid Ad-Dharuriyyah).

Menurut penelitian Abu Ishaq al Syatibi Tingkatan masqashid syariah sebagaimana dirumuskan dalam lima atau enam pilar diatas terbagi menjadi tiga martabat (tingkatan) antara lain:

(1). Kebutuhan Dharuriyat (Primer) adalah yang menjadi dasar tegaknya kehidupan asasi manusia baik yang berkaitan dengan agama maupun dunia yang termasuk kedalam kebutuhan ini adalah ada lima macam, yaitu hal-hal yang berkaitan dengan pemeliharaan agama, jiwa, akal, keturunan dan harta. Umumnya ulama ushul fiqh sependapat tentang lima hal tersebut sebagai maslahat yang paling asasi.

(2). Kebutuhan hajjiyat (Sekunder) adalah segala sesuatu yang oleh hukum syara' tidak dimaksudkan untuk memelihara lima hal pokok tadi, akan tetapi dimaksudkan untuk menghilangkan kesulitan, kesusahan, kesempitan dan ihtiyath (berhati-hati) terhadap lima hal pokok tersebut. 
(3). Kebutuhan Tahsiniyat (Tersier) atau (Pelengkap) ialah tingkat kebutuhan yang apabila tidak terpenuhi tidak mengancam eksistensi salah satu dari kelima pokok diatas serta tidak pula menimbulkan kesulitan.

\section{Maqashid Syariah Index}

Maqashid Syariah Index (MSI) adalah metode pengukuran kinerja perbankan syariah yang dikembangkan oleh Mohammed, Dzuljastri dan Taif (2008). Dalam penelitian tersebut dirumuskan evaluasi kinerja untuk perbankan syariah yang mengacu pada konsep maqashid syariah. Pengembangan metode Maqashid Syariah Index (MSI) didasari ketidaksesuaian penggunaan indikator kinerja konvensional apabila diterapkan pada perbankan syariah. Ketidaksesuaian tersebut disebabkan oleh perbedaan tujuan antara indikator pengukuran konvensional yang lebih menitikberatkan pada pengukuran kinerja keuangan dibandingkan indikator pengukuran perbankan syariah yang lebih bersifat multi dimensional.

Para ulama Fiqih memiliki perbedaan pendapat atau pandangan dalam melakukan klasifikasi terhadap konsep pengukuran maqashid (tujuan/maksud) syariah. Konsep pengukuran kinerja Maqashid Syariah Index (MSI) dalam penelitian ini membandingkan antara konsep pengukuran kineja Maqashid Syariah Index (MSI) menurut Abu Zahrah dan Konsep pengukuran kinerja Maqashid Syariah Index (MSI) Abbul Majjid Najjar.

\section{Konsep Maqashid Syariah (MSI) Abu Zahrahh}

Konsep Maqashid Syariah Abu Zahrahh.Dalam kitab Ushul Fiqihnya beliau merumuskan konsep maqashid syariah kemudian mengklasifikasikannya ke dalam tiga tujuan utama yaitu: (1). Tahdzib al fard (Pendidikan individu), (2). Iqamah al-adl (Menegakkan keadilan), (3). Jalb al maslahah (Mewujudkan kemaslahatan/Kepentingan Umum). Ketiga konsep Abu Zahrah digunakan dan dikembangkan oleh Mohammed and Taib (2015), seperti terlihat pada tabel 2.1. Maqashid syariah index Abu Zahrah berikut:
Tabel 2.1. Maqashid syariah Abu Zahrah

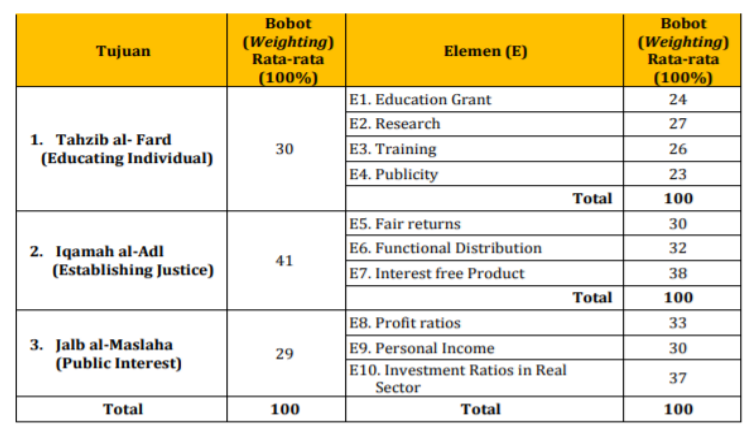

Sumber : Mohammed and Taib (2015)

Penjelasan konsep Maqashid Syariah Index (MSI) Abu Zahrahh sebagaimana telah dikembangkan oleh Mohammed and Taib (2015), secara ringkas terdiri atas :

(1) Tahdzib al fard (Pendidikan individu). Indikator Kinerja pendidikan individu berorientasi pada Bank syariah dituntut untuk berperan serta dalam mengembangkan pengetahuan tidak hanya bagi pegawainya tetapi juga masyarakat banyak. Pengukuran kinerja pada dimensi ini meliputi 4 elemen pengukuran: E1.Hibah Pendidikan, E2. Penelitian, E3.

(2) Iqamah al-adl (Menegakkan keadilan). Indikator Kinerja menegakan keadilan beorientasi kepada Bank syariah dituntut untuk dapat melakukan transaksi secara adil dan setara sehingga yang tidak merugikan nasabahnya. Pengukuran kinerja pada dimensi ini meliputi 3 elemen pengukuran : E5. Pemgembalian yang adil, E6. Distribusi fungsional, dan E7.Produk bebas bunga Pendidikan, dan E4. Publikasi.

(3) Jalb al maslahah (Mewujudkan kemaslahatan atau Kepentingan Umum). Indikator Kinerja kepentingan umum berorientasi kepada bahwa semakin besar keuntungan yang diperoleh bank syariah akan berdampak pada peningkatan kesejahteraan tidak hanya pemilik, dan pegawai bank syariah, tetapi berdampak pula pada semua stakeholder perbankan syariah. Pengukuran kinerja pada dimensi ini meliputi 3 elemen pengukuran: E8. Profit rasio, E9. Pendapatan personal, E10. Investasi pada sector riil. Selengkapnya konsep pengukuran Magashid syariah index (MSI) Abu Zahrah sebagaimana telah dikembangkan oleh Mohammed and Taib (2015) 


\section{Konsep Maqashid Syariah (MSI) AM Najjar}

Konsep lain terhadap konsep pengukuran maqashid (tujuan/maksud) syariah Index (MSI) diambil berdasarkan konsep maqasid syariah yang dikemukakan Abdul Majid Najjar. Pengukuran kinerja konsep Maqashid Syariah (MSI) AM Najjar dikembangkan oleh (Bedoui 2012) dalam muthia dan musfirah (2017) dinilai merupakan konsep maqashid shariah dengan pembahasan yang lebih comprehensive, dengan cakupan lebih luas dan lebih efektif. Hal ini dilihat berdasarkan indikator kinerja yang ingin diungkapkan. AM Najjar membagi maqashid syariah kedalam 4 tujuan utama (objektif) kemudian mengukurnya kedalam 8 elemen konsekuensi seperti terlihat pada tabel 2.2 berikut:

Tabel 2.2. Maqashid syariah AM Najjar

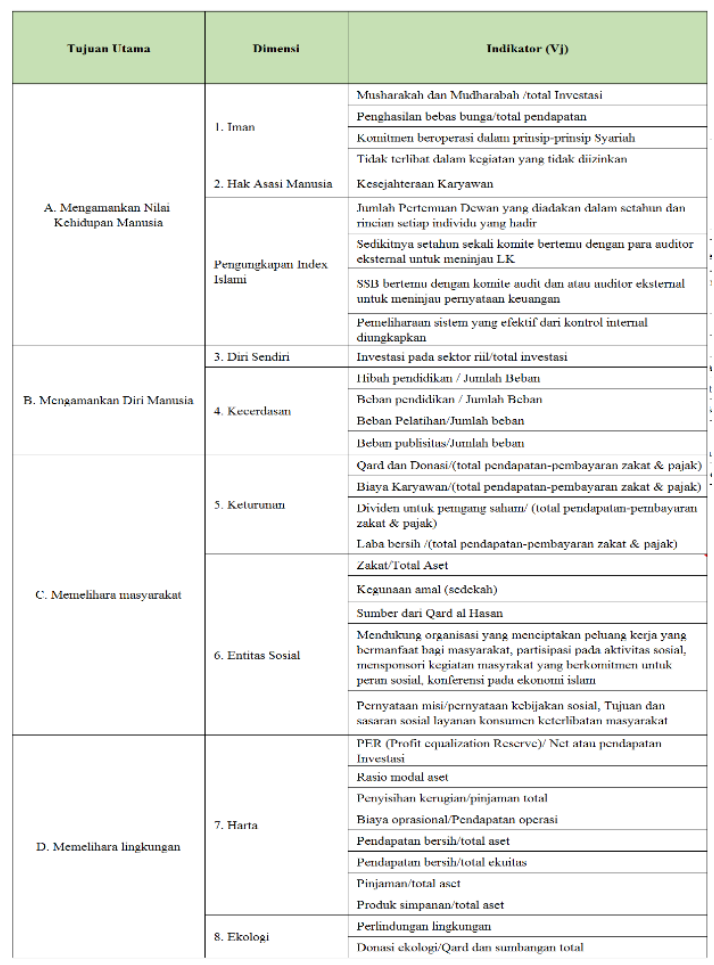

Sumber: Bedoui (2012)

Penjelasan atas konsep Maqashid Syariah Index (MSI) yang dikembangkan oleh AM Najjar terdiri dari 4 tujuan utama (objektif), setiap tujuan terdapat 2 dimensi, tiap dimensi terdiri atas beberapa elemen, namun setiap elemen hanya memiliki satu indikator sebagai rasio pengukuran, dengan penambahan pengungkapan indeks islami (islamicity disclosure index), dan rasio kesehatan perbankan. Indikator kinerja (tujuan)
Maqashid Syariah Index (MSI) AM Najjar terdiri atas :

(1) Mengamankan Nilai Kehidupan Manusia. Indikator Kinerja tujuan pertama Mengamankan nilai kehidupan manusia berorientasi kepada dimensi Iman dan Hak Azasi Manusia (HAM) dan Islamicity Disclosure Indeks. Pengukuran Tujuan/Maksud mengamankan nilai kehidupan Manusia. sesuai Konsep-konsep yang diperkenalkan oleh Mohammed et al. (2008), Haniffa \& Hudaib (2007), dan Hameed et al. (2004), dalam mengukur ratio dan pengungkapan elemen-elemen distribusi fungsional, penghasilan halal non bunga, komitmen pada prinsip-prinsip syariah, komitmen tidak terilbat pada kegiatan-kegiatan yang melanggar syariah, komitmen pada kesejahteraan karyawan, dan komitmen pada pengungkapan islamicity index.

(2) Mengamankan Diri Manusia. Indikator Kinerja tujuan kedua adalah mengamankan diri manusia, terdapat konsekuansi diri manusia dan kecerdasan). Konsep pengukuran dikembankan oleh Mohammed et al. (2008). Dimensi diri manusia memiliki sebuah indikator untuk mengukur kontribusi perbankan syariah dalam pemberdayaan ekonomi sektor riil. Menurut Aizenman et al. (2011), pembiayaan sektor keuangan (termasuk asuransi dan real estate) harus dikeluarkan untuk melakukan perhitungan. Dimensi kecerdasan meliputi 4 indikator untuk mengukur alokasi dana dalam mendidik individu, seperti : dana pendidikan, penelitian, pelatihan, dan publisitas

(3) Mengamankan Masyarakat Indikator Kinerja tujuan ketiga adalah mengamankan masyarakat terdiri dari 2 dimensi yaitu : dimensi keturunan dan entitas sosial. Dalam keturunan, menerapkan 4 indikator indeks kuantitatif. Konsep pengukuran yang dikembangkan oleh (Hameed et al. 2004) untuk mengukur seberapa baik lembaga yang memenuhi kebutuhan pemegang kepentingan untuk menghapuskan faktor seperti ketakutan dan konflik-konflik (Chapra 2008). Dalam dimensi entitas 
sosial, menerapkan 4 indikator indeks kualitatif.

(4) Mengamankan Lingkungan. Indikator Kinerja tujuan keempat adalah menjaga lingkungan meliputi 2 dimensi yaitu : kekayaan dan ekologi (lingkungan). Dimensi kekayaan mengadopsi analisis yang dikhususkan untuk menilai rasio kesehatan perbankan menggunakan konsep CAMEL: Capital (modal), Asset quality (kualitas aktiva), Management (manajemen), Earning (pendapatan), dan Liquidity (likuiditas) (Jaffar dan Marnavi 2011). Rasio kesehatan perbankan dapat pula menggunakan RGEC (risk profile, $G C G$, Earning, and Capital) sebagai index kesehatan perbankan terbaru. Menurut Hameed et al. (2004) indikator untuk dimensi ekologi (lingkungan) menyarankan berupa nilai komitmen dalam isu-isu lingkungan untuk perlindungan lingkungan, dan alokasi dana CSR untuk menghitung nilai sumbangan (Donasi ekologi )/Qard untuk lingkungan melalui sumbangan total.

\section{Metode Penelitian}

\section{Desain Penelitian}

Desain penelitian ini bersifat studi eksplorasi, dimana data diperoleh dan dianalisis melalui secara kuantitatif dan kuantitif.

\section{Populasi Dan sampel}

Teknik pengambilan sampel dengan metode purposive sampling, dengan tujuan dapat diperoleh sampel yang representative sesuai dengan kriteria yang diharapkan peneliti. Menurut (Arikunto,:2010) pengambilan sampel dengan metode ini cukup baik karena pengambilan sampel dilakukan sesuai dengan tujuan yang dikehendaki.

Kriteria sampel yang akan digunakan dalam penelitian ini adalah sebagai berikut: (1) Bank Umum Syariah yang beroperasi secara nasional di Indonesia, dan terdaftar pada otoritas jasa keuangan (OJK) re-publik Indonesia,(2) Bank Umum Syariah secara konsisten menyajikan laporan tahunan (annual report) publikasi periode 2014-2018 di website resmi masing-masing bank sesuai dengan kriteria tertentu yang di-harapkan peneliti yaitu merupakan bank syariah yang sejak awal beroperasi berstatus sebagai bank syari-ah.Berdasarkan kriteria pemilihan sampel tersebut diperoleh bank syariah yang dijadikan sampel penelitian ini berjumlah 1 bank syariah.

Berdasarkan Uji Autokorelasi, bahwa nilai Durbin-Watson sebesar 1,786. Dari tabel DW dengan nilai signifikansi 0,05 dan jumlah data $(\mathrm{n})=55$, serta $\mathrm{k}=5$ (jumlah variabel independen) diperoleh nilai DU sebesar 1,7681 dan nilai dl sebesar 1,3743. Dikarenakan DW lebih besar dari DU dan lebih kecil dari 5-DU $(5-1,7681=3,23)$, maka dapat disimpulkan tidak terjadi autokorelasi.

Tabel 3.1. Kriteria Sampel Penelitian

\begin{tabular}{|c|l|c|}
\hline No & \multicolumn{1}{|c|}{ KRITERIA SAMPLE } & JUMLAH \\
\hline 1 & $\begin{array}{l}\text { Bank Umum Syariah yang beroperasi secara nasional } \\
\text { di Indonesia, dan terdaftar pada OJK Republik } \\
\text { Indonesia }\end{array}$ & 14 \\
\hline 2 & $\begin{array}{l}\text { Bank Umum Syariah yang tidak sesuai dengan kriteria } \\
\text { tertentu yang diharapkan peneliti }\end{array}$ & $(13)$ \\
\hline 3 & Bank Umum Syariah (BUS) sampel penelitian & 1 \\
\hline 4 & Periode Tahun Pengamatan & 5 \\
\hline 5 & Jumlah Data Penelitian & 5 \\
\hline Sumber $:$ tabel hasil olah data
\end{tabular}

\section{Sumber dan Teknik Pengumpulan Data}

Jenis data yang digunakan dalam penelitian ini adalah data sekunder. Menurut Umar (2007) data sekunder merupakan data primer yang telah diolah lebih lanjut. Data sekunder yang dimaksud dalam penelitian ini adalah laporan tahunan (annual report) meliputi: laporan keuangan, laporan manajemen, laporan pelaksanan GCG, berupa satu kesatuan maupun laporan terpisah selama periode tahun 2014-2018 yang telah dipublikasi di website resmi masing-masing bank yang menjadi objek penelitian. Sampel Bank Syariah yang digunakan dalam penelitian ini adalah Bank Muamalat Indonesia (BMI).

\section{Mengukur Kinerja Maqashid Syariah (MSI) Maqashid Syariah Index (MSI) Abu Zahrahh}

Dalam menyusun pendekatan maqashid syariah index (MSI), Mohammed, Dzuljastri dan Taif (2008) dalam hartono (2018) menggunakan metode metode Sekaran untuk menentukan indikator pengukuran. Untuk mendapatkan hasil yang terbaik dalam pengukuran maqashid syariah index (MSI), 
dilakukan verifikasi terhadap model dan pembobotan dari setiap konsep dan elemen pengukuran sebagaimana yang disajikan pada tabel berikut:

Tabel 3.2. Tabel Maqashid Syariah Index Abu Zahrah

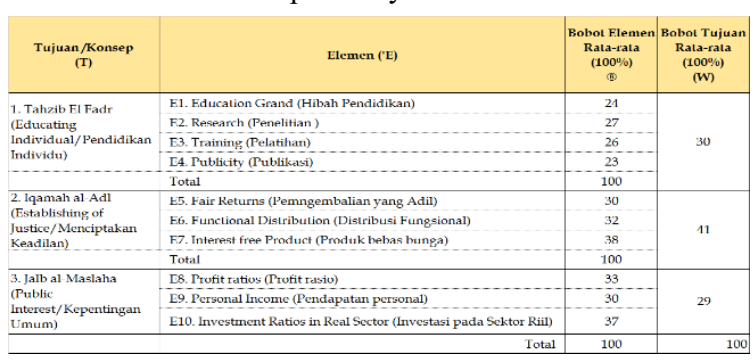

Sumber : Mohammed dan Taib (2015)

Mengukur indikator kinerja (IK) maqashid syariah index (MSI) bank syariah dalam konsep ini dilakukan melalui 3 tahapan pengukuran, yaitu:

(1) Menilai setiap elemen rasio kinerja maqashid syariah,

(2) Menentukan peringkat dari bank syariah berdasarkan Indikator Kinerja (IK). Proses tersebut dilakukan dengan menggunakan Simple Additive Weighting Method (SAW). Melalui pembobotan (weighting), pengumpulan (agregat), dan proses menentukan peringkat (ranking processes). Konsep dasar metode Simple Additive Weighting Methode (SAW) dengan mencari penjumlahan terbobot dari rating setiap tujuan pada semua atribut yang disebut dengan Multiple Attribute Decision Making (MADM). Secara matematis, proses menentukan indikator kinerja dan tingkat indeks maqasid syariah tersebut dapat dijelaskan sebagai berikut (Mohammed, Dzuljastri dan Taif, 2008):

(2a) Mengukur Indikator Kinerja (IK) Tujuan pertama yaitu Mendidik Individu (Tahzib al-Fard):

$\mathrm{I} K\left(T_{1}\right)=W{ }^{1_{1}}\left(E^{1}{ }_{1} x R^{1}{ }_{1}+E^{2}{ }_{1} x R^{2}{ }_{1}+E^{3}{ }_{1} x R^{3}{ }_{1}+E^{4}{ }_{1} x R^{4}{ }_{1}\right)$

Dalam hal ini :

$\mathrm{T}_{1} \quad=$ Tujuan ke-1 MSI (Tahzib al Fard)

$\mathrm{W}^{1}{ }_{1}=$ Bobot rata-rata tujuan ke -1

$\mathrm{E}^{\mathbf{1}} \mathbf{1}=$ Rasio kinerja Elemen ke-1 Tujuan ke-1

$\mathrm{E}^{2}{ }_{1}=$ Rasio kinerja Eemen ke-2 Tujuan ke-1

$\mathrm{E}^{3}{ }_{1}=$ Rasio kinerja Elemen ke-3 Tujuan ke-1

$\mathrm{E}^{4}{ }_{1}=$ Rasio kinerja Elemen ke-4 Tujuan ke-1

$\mathrm{R}^{1}{ }_{1} \quad=$ Bobot rata-rata (E1.Donasi beasiswa)

Tujuan ke-1

$\mathrm{R}^{2}{ }_{1}=$ Bobot rata-rata (E2.Penelitian) Tujuan ke-1

$\mathrm{R}^{3}{ }_{1}=$ Bobot rata-rata (E3.Pelatihan) Tujuan ke-1

$\mathrm{R}^{4}{ }_{1}=$ Bobot rata-rata (E4.Publikasi) Tujuan ke-1 (2b) Mengukur Indikator Kinerja (IK) Tujuan kedua yaitu Menciptakan Keadilan (Iqamah al-Adl):

$\mathrm{I} K\left(T_{2}\right)=W^{2}{ }_{2}\left(E^{5}{ }_{2} \times R^{5}{ }_{2}+E^{6}{ }_{2} \times R^{6}{ }_{2}+E^{7}{ }_{2} \times R^{7}{ }_{2}\right)$

Dalam hal ini :

$\mathrm{T}_{2}=$ Tujuan ke 2 (T2) MSI (Iqamah al-Adl)

$\mathrm{W}^{2}{ }_{2}=$ Bobot rata-rata tujuan ke 2 (T2)

$\mathrm{E}^{5}{ }_{2}=$ Rasio kinerja Elemen ke-5 Tujuan ke-2

$\mathrm{E}_{2}^{6}=$ Rasio kinerja Elemen ke-5 Tujuan ke-2

$\mathrm{E}_{2}^{7}=$ Rasio kinerja Elemen ke-5 Tujuan ke-2

$\mathrm{R}^{5}{ }_{2}=$ Bobot rata-rata (E5.Pengembalian yang adil)

Tujuan ke-2

$\mathrm{R}^{6}{ }_{2}=$ Bobot rata-rata (E6. Fungsi distribusi) Tujuan ke-2

$\mathrm{R}_{2}^{7}=$ Bobot rata-rata (E7. Produk bebas bunga) Tujuan ke-2

(2c) Mengukur Indikator Kinerja (IK) Tujuan ketiga yaitu Kepentingan Umum (Jalb al Maslahah):

$I K\left(T_{3}\right)=W^{3}{ }_{3}\left(E^{8}{ }_{3} x R^{8}{ }_{3}+E^{9}{ }_{3} x R^{9}{ }_{3}+E^{10_{3}} x R^{10_{3}}\right)$

Dalam hal ini :

$\mathrm{T}_{3}=$ Tujuan ketiga dari MSI (Jalb al Maslahah)

$\mathrm{W}^{\mathbf{3}}{ }_{\mathbf{3}}=$ Bobot rata-rata tujuan ke-3

$\mathrm{E}_{\mathbf{3}}^{\mathbf{8}}$ = Rasio kinerja Elemen ke-8 Tujuan ke-3

$\mathrm{E}^{9} \mathbf{3}_{\mathbf{3}}=$ Rasio kinerja Elemen ke-9 Tujuan ke-3

$\mathrm{E}^{\mathbf{1 0}}{ }_{\mathbf{3}}=$ Rasio kinerja Elemen ke-10 Tujuan ke-3

$\mathrm{R}^{\mathbf{8}} \mathbf{3}_{\mathbf{3}}=$ Bobot rata-rata (E8. Rasio profit) Tujuan ke3

$\mathrm{R}^{9}{ }_{3}=$ Bobot rata-rata (E9.Pendapatan personal) Tujuan ke-3

$\mathrm{R}^{\mathbf{1 0}_{3}}=$ Bobot rata-rata (E10.Investasi di sektor rill) Tujuan ke-3

(3) Menghitung nilai (skoring) maqasid syariah indeks (MSI). Tahap selanjutnya adalah menghitung nilai maqashid syariah indeks (MSI) bank syariah yang menjadi objek penelitian dengan menjumlahkan seluruh indikator kinerja pengukuran dengan formulasi sebagai berikut:

$$
\mathrm{MSI}=\mathrm{IK}\left(\mathrm{T}_{1}\right)+\mathrm{IK}\left(\mathrm{T}_{2}\right)+\mathrm{IK}\left(\mathrm{T}_{3}\right)
$$

Dalam hal ini :

MSI = Nilai indeks maqasid syariah

$\operatorname{IK}\left(T_{1}\right)=$ Total indikator kinerja tujuan pertama (mendidik individu)

$\operatorname{IK}\left(\mathrm{T}_{2}\right)=$ Total indikator kinerja tujuan kedua (menciptakan keadilan)

IK $\left(T_{3}\right)=$ Total indikator kinerja tujuan ketiga (kepentingan umum) 


\section{Maqashid Syariah Index (MSI) AM Najjar}

Menghitung kinerja Maqashid Syariah Index (MSI) AM Najjar pada penelitian ini dilakukan melalui beberapa tahapan pengukuran:

(1) Menghitung nilai (skoring) rata-rata selama 5 tahun penelitian untuk setiap indikator kinerja dengan metode kuantitatif menggunakan rasio dengan pendekatan hasil penelitian Mohammed et al. (2008) dan Hameed et al. (2004).Untuk indikator kinerja dengan metode kualitatif berupa pengungkapan atau pernyataan pendekatan penilaian kinerja menggunakan referensi hasil penelitian Haniffa dan Hudaib (2007), yaitu nilai 1 apabila pengungkapan dilakukan dan nilai 0 apabila pengungkapan tidak dilakukan.(Bedoui 2012) dalam Muthia dan Musrifah (2017). Tabulasi pengukuran indikator kinerja Maqashid Syariah Index (MSI) AM Najjar dapat dilihat pada lampiran 2.

(2) Langkah berikutnya adalah melakukan perkalian antara 8 bobot konsekuensi pengukuran dari setiap variabel dengan nilai (skoring) per elemen untuk masing-masing indikator kinerja. Bobot konsekuensi per elemen untuk masing-masing indikator kinerja penelitian dapat dilihat pada Lampiran 3.

(3) Menghitung indikator kinerja (IK) Maqashid Syariah Index (MSI) secara matematis menggunakan model perhitungan indikator kinerja berupa perkalian nilai setiap dimensi dengan bobot per elemen konsekuansi sehingga menghasilkan nilai (skoring) untuk masing-masing dimensi sesuai dengan konsep Simple Additive Weighting Method (SAW) dari rating setiap tujuan pada semua atribut yang disebut dengan Multiple Attribute Decision Making (MADM) (Yoon and Hwang 1955) mengunakan formulasi sebagai berikut:

$$
V(A i)=V i=\sum_{j=1}^{n} W j V j(X i j), i, \ldots, m
$$

Dalam hal ini :

$\mathrm{Vi}=$ Nilai dari setiap dimensi

$\mathrm{Wj} \quad=$ Bobot untuk setiap elemen

$\mathrm{Vj}(\mathrm{Xij})=$ Rasio kinerja untuk setiap elemen
(4) Setelah nilai (skoring) perkalian diperoleh, langkah selanjutnya adalah melakukan perhitungan indikator kinerja (IK) maqashid shariah index (MSI) secara keseluruhan dengan menggunakan vector penjumlahan (Bedoui, 2012). Langkah berikutnya adalah melakukan penentuan peringkat bank syariah yang menjadi objek penelitian dengan cara menjumlahkan total seluruh indikator kinerja dari empat variabel maqashid shariah index.

\section{Hasil Penelitian dan Pembahasan}

\section{Hasil Penelitian}

Seperti yang dijelaskan pada bab pendahuluan bahwa ini akan mengukur kinerja dari perbankan sya-riah di yang beroperasi di Indonesia dan terdaftar pada otoritas jasa keuangan (OJK) Republik Indonesia. Populasi perbankan syariah di Indonesia sampai dengan tahun 2019 terdaftar sebanyak 14 Bank Syariah. Sebagian besar bank syariah adalah berasal dari bank umum nasional yang membentuk unit syariah sebagai cikal berdirinya bank syariah. Hanya terdapat 1 bank syariah yang sejak awal berdirinya sudah memiliki ijin sebagai bank umum pertama yang berbasis kepada prinsip syariah. Bank Muamalat Syariah Indonesia memulai bisnisnya pada 1 November 1991 atau 24 Rabi'us Tsani 1412 Hijriah. Berdasarkan hasil penguku-ran kinerja Bank Mualamat syariah Indonesia (BMSI) menggunakan 2 model pengukuran kinerja (per-formance) maqashid syariah index baik menggunakan konsep abu Zahrah maupun konsep AM Najjar di-peroleh hasil penghitungan indeks kinerja magashid syariah untuk Bank Mualamat syariah Indonesia (BMSI) sebagai berikut:

\section{Pembahasan}

\section{Skor Indikator Kinerja Maqashid syariah Index BMSI tahun 2014 sd 2018 Abu Zahrah}

Berdasarkan hasil analisa maka nilai tertinggi untuk indikator kinerja (IK) maqashid syariah index (MSI) tujuan pertama (IK-T1) adalah Tahzib El Fadr (Educating Individual/Pendidikan Individu) terjadi pada tahun 2016 sebesar 7.78\%. Nilai tertinggi indikator kinerja (IK) maqashid syariah index 
(MSI) tujuan kedua (IK-T2) Iqamah al-Adl (Establishing of Justice/Menciptakan Keadilan) terjadi pada tahun 2015 sebesar $19,98 \%$, sedangkan nilai tertinggi indikator kinerja (IK) maqashid syariah index (MSI) tujuan ketiga (IK-T3) Jalb al-Maslaha (Public Interest/Kepentingan Umum) terjadi pada tahun 2017 sebesar 5.56\%. Secara keseluruhan tingkat performa MSI BMI adalah tertinggi adalah sebesar $34.87 \%$ terjadi pada tahun 2017 sedangkan rata-rata MSI BMI untuk tahun 2014 -2018 adalah 35.65\%. Tabel 4.1 menunjukan nilai skor MSI performance untuk BSM pada tahun 2014 hingga 2018 menurut konsep MSI Abu Zahrah.

Tabel 4.1 Skor Kinerja MSI Abu Zahrah

\begin{tabular}{|c|c|c|c|c|}
\hline \multirow{3}{*}{ TAHUN } & \multicolumn{3}{|c|}{ Indikator Kinerja } & \multirow{3}{*}{$\begin{array}{c}\text { MSI } \\
\text { PERFORMANCE }\end{array}$} \\
\hline & IK (T1) & IK (T2) & IK (T3) & \\
\hline & 1 & 2 & 3 & \\
\hline 2014 & 0.2130 & 0.1923 & 0.0370 & 0.4423 \\
\hline 2015 & 0.1684 & 0.1998 & 0.0162 & 0.3844 \\
\hline 2016 & 0.0778 & 0.1970 & 0.0156 & 0.2903 \\
\hline 2017 & 0.0730 & 0.1879 & 0.0556 & 0.3164 \\
\hline 2018 & 0.1333 & 0.1934 & 0.0221 & 0.3487 \\
\hline
\end{tabular}

Sumber : Laporan tahunan diolah

Nilai indikator kinerja (performance) MSI menurut konsep Abu Zahrah hanya mengukur kinerja bersifat data kuantitatif. Rasio dihitung berdasarkan nilai masing-maisng per elemen rasio pengukuran kemudian dikalikan dengan bobot per elemen lalu dikalikan dengan bobot per tujuan. Tabel 4.1. Nilai indikator kinerja (performance) MSI menunjukan fluktuasi kinerja yang cenderung menurun. Berbagai faktor bisa menjadi penyebab fluktuasi nilai kinerja MSI (performance). Transparansi terhadap investasi sector riil dan nilai hibah pendidikan memerlukan penngungkapan yang lebih jelas dan pernyataan yang lebih tegas. Grafik 4.1 berikut dapat memberikan gambaran lebih jelas mengenai indikator kinerja (performance) MSI BMSI untuk tahun 20142018.
Gambar 4.1. Skor Kinerja MSI 2014-2018

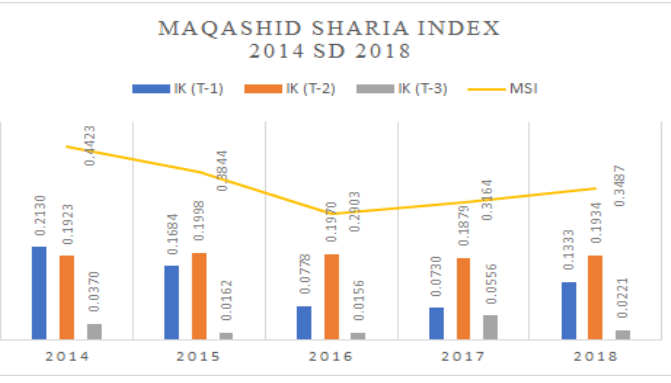

Sumber : Laporan tahunan diolah

\section{Skor Indikator Kinerja Maqashid syariah Index BMI tahun 2014 sd 2018 AM Najjar}

Nilai tertinggi kinerja (performance) MSI indikator kinerja (IK) maqashid syariah index (MSI) tujuan pertama (IK-T1) Mengamankan nilai kehidupan Manusia terjadi pada tahun 2016 sebesar $8.52 \%$. Nilai tertinggi indikator kinerja (IK) maqashid syariah index (MSI) tujuan kedua (IK-T2) Mengamankan Diri Manusia terjadi pada tahun 2014 sebesar $2.95 \%$. Nilai tertinggi indikator kinerja (IK) maqashid syariah index (MSI) tujuan ketiga (IK-T3) Memelihara masyarakat terjadi pada tahun 2015 sebesar 13.73\%. Nilai tertinggi indikator kinerja (IK) maqashid syariah index (MSI) tujuan keempat (IK-T4) Memelihara lingkungan terjadi pada tahun 2018 sebesar $15.15 \%$. Secara keseluruhan nilai kinerja (performance) MSI BMI adalah tertinggi adalah sebesar $37.76 \%$ terjadi pada tahun 2018. sedangkan rata-rata nilai kinerja (performance) MSI BMSI tahun 2014-2018 adalah 30.56.\%. Hasil pengukuran dapat dilihat pada tabel 4.2 berikut:

Tabel 4.2. Skor Kinerja MSI AM Najjar

\begin{tabular}{|r|r|r|r|r|r|}
\hline Tahun & IK (T1) & IK (T2) & IK (T3) & IK (T4) & $\begin{array}{c}\text { MSI } \\
\text { PERFORMANCE }\end{array}$ \\
\hline 2014 & 8.4960 & 2.9579 & 12.1796 & 3.0197 & 26.6531 \\
\hline 2015 & 8.5216 & 2.3364 & 13.7271 & 2.6890 & 27.2742 \\
\hline 2016 & 8.5225 & 1.0267 & 12.2524 & 2.6500 & 24.4516 \\
\hline 2017 & 8.4816 & 1.0137 & 12.2354 & 14.9696 & 36.7003 \\
\hline 2018 & 8.4852 & 1.8504 & 12.2752 & 15.1504 & 37.7612 \\
\hline
\end{tabular}

Sumber : laporan tahunan data diolah 
Konsep pengukuran nilai indikator kinerja (performance) MSI menurut konsep AM Najar sebenarnya berbeda dengan cara pengukuran kinerja (performance) MSI menurut konsep Abu Zahrah. Apabila konsep kinerja (performance) MSI lebih menitikberatkan pada pengukuran berdasarkan tujuan pokok maqashid syariah berdasarkan bobot rata-rata per tujuan pokok sebagaimana konsep yang dikembangkan Mohammed and Taib (2015). Konsep pengukuran nilai indikator kinerja (performance) MSI menurut konsep AM Najar tidak berdasarkan kepada bobot per tujuan pokok, namun lebih menitikberatkan pada nila bobot per masing-masing elemen yang terbadi kedalam 8 elemen dengan skor bobot yang sudah ditentukan seperti terlihat pada lampiran 3. Cara untuk mengukur kinerja (performance) MSI konsep AM Najjar sebagaimana terlihat pada tabel 4.3 kinerja (performance) MSI bobot per elemen seperti berikut ini:

Tabel 4.3. Skor Kinerja (Performance) MSI per elemen

\begin{tabular}{|c|c|c|c|c|c|c|c|c|c|}
\hline \multirow[b]{2}{*}{ TAHUN } & \multicolumn{8}{|c|}{ Kinerja MSI per elemen } & \multirow{2}{*}{$\begin{array}{c}\text { MSI } \\
\text { PERFORMANCE }\end{array}$} \\
\hline & Iman & HAM & Diri Sendiri & kecerdasan & Keturunan & Entitas Sosial & Harta & Ekologi & \\
\hline 2014 & 3.7488 & 6.5008 & 1.2724 & 3.0994 & 1.1448 & 5.3494 & 4.2053 & 1.3321 & 26.6531 \\
\hline 2015 & 3.7565 & 6.5115 & 1.2756 & 2.7889 & 2.5910 & 5.0258 & 3.9523 & 1.3726 & 27.2742 \\
\hline 2016 & 3.7568 & 6.6356 & 1.2822 & 2.0167 & 1.1591 & 4.3894 & 3.9027 & 1.3090 & 24.4516 \\
\hline 2017 & 3.7445 & 6.4950 & 1.2784 & 2.1347 & 1.1652 & 8.0806 & 3.8504 & 9.9515 & 36.7003 \\
\hline 2018 & 3.7456 & 6.4978 & 1.2849 & 2.5578 & 1.1661 & 8.5217 & 4.0066 & 9.9806 & 37.7612 \\
\hline AVG & 3.7504 & 6.5281 & 1.2787 & 2.5195 & 1.4453 & 6.2734 & 3.9835 & 4.7892 & 30.5681 \\
\hline
\end{tabular}

Sumber : laporan tahunan data diolah

Pada tabel 4.3 Skor Kinerja (Performance) MSI per elemen terlihat nilai tertinggi untuk elemen ke-1 iman dan Hak azasi manusia (HAM) terjadi pada tahun 2016 senilai $3.75 \%$ dan $6.63 \%$. Nilai elemen Diri sendiri tertinggi pada tahun 2018 sebesar $1.28 \%$. Nilai selanjutnya untuk elemen kecerdasan tertinggi pada tahun 2016 sebesar $18.82 \%$. Elemen keturunan tertinggi terjadi pada tahun $25.91 \%$. Untuk entitas sosial nilai tertinggi sebesar $76.05 \%$ terjadi pada tahun 2018. Elemen harta tertinggi terjadi pada tahun 2014 sebesar $42.53 \%$, dan nilai elemen ekologi tertinggi terjadi pada tahun 2018 sebesar $99.80 \%$. Nilai kinerja (performance) MSI tertinggi berada pada tahun 2018 sebesar $35.93 \%$. Rata-rata nilai kinerja (performance) MSI BMI untuk tahun 2014-2018 adalah 28.94\%.

Nilai indikator kinerja (performance) MSI menurut konsep AM Najjar mencakup pengukuran indikator kinerja hanya mengukur kinerja (performance) MSI yang lebih komprehensive, lebih meluas dan efektive meskipun menimbulkan konsekuensi pembahasan yang lebih mendalam kerana didalamnya tercakup pul pengukuran berupa pernyataan atau komitmen yang lebih bersifat data kualitatif. Gambar 4.2. berikut ini mencoba memperlihatkan sudut analisis yang berbeda dengan menampilkan hasil pengukuran berupa graphic yang memperlihatkan potongan-potongan elemen -elemen yang merupakan indikator kinerja performance) MSI sebagai satu kesatuan yang utuh.
Hal ini dimaksudkan agar analisis tidak hanya terfokus pada tampilan berupa rasio atau prosentase namun dalam bentuk graphis untuk memudahkan melakukan analisa data.

Gambar 4.2. Graphic kinerja MSI AM Najjar

KINERJA MSI 2014-2018

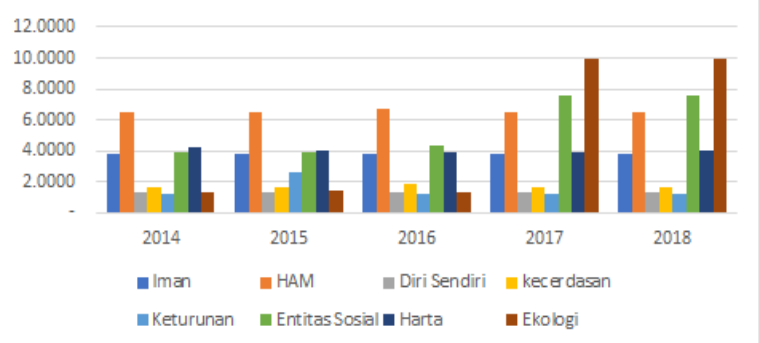

Potongan-potongan (slice) grafik kinerja MSI AM Najjar diatas menggambarkan porsi masing-masing elemen dari total 8 elemen pengukuran dalam bentuk prosentase yang diolah berdasarkan prosentase masing-masing bobot per elemen.

Tabel 4.3. Skor kinerja (performance) MSI berdasarkan bobot per elemen pengukuran menunjukan peningkatan kinerja sejak tahun 2014 hingga 2018 sekitar 15.21\%. Peningkatan tertinggi dari ke 8 elemen bisa terlihat pada elemen ekologi yang meningkat cukup signifikan ini menunjukan bahwa kinerja bank syariahvterhadap kepedulian lingkungan (CSR) cukup besar sejak tahun 2014 hingga 2018. 
Tabel 4.2. Skor Kinerja MSI AM Najjar menunjukan bentuk lain dari analisa penilaian kinerja (performance) MSI AM Najjar selain analisa berdasarkan yang tidak berdasarkan elemen-elemen MSI, pengukuran nilai kinerja (performance) MSI namun dilakukan dalam bentuk pengungkapan lain, seperti pengukuran berdasarkan 4 tujuan pokok maqashid syariah AM Najjar, yaitu: mengamankan nilai kehidupan manusia, mengamankan diri manusia, mengamankan masyarakat dan mengamankan lingkungan Penilaian kinerja (performance) MSI berdasarkan konsep MSI AM Najjar terdiri atas atas 4 tujuan pokok, yaitu:

\section{Indikator Kinerja Tujuan pertama (IK-T1) Maqashid Shariah adalah mengamankan Nilai Kehidupan Manusia}

Pada tujuan pertama maqashid shariah index terbagi atas dua elemen yaitu iman dan hak asasi manusia BMI sejak tahun 2014 hingga tidak mengalami pergerakan yang signifikan cenderung datar. Melalui tujuan pertama ini bank syariah ingin memastikan bahwa komitmen mereka dalam menjalankan kegiatan operasionalnya sesuai dengan prinsip syariah yang telah ditentukan. Pada elemen kedua, yaitu hak asasi manusia (HAM) terbagi dalam beberapa dimensi, untuk melihat apakah perbankan syariah telah melaksanakan tata kelola perusahaannya dengan baik dari aspek produk yang bebas bunga, karyawan, direksi, komite, SSB, dan aspek lainnya. Pencapaian nilai kinerja (performance) MSI untuk tujuan pokok pertama (IK-T1) antara tahun 2014-2018 mencapai $8.45 \quad-8.5 \%$ menunjukan komitmen BSMI dalam menjalankan kegiatan operasionalnya sesuai dengan prinsip syariah.

\section{Indikator Kinerja Tujuan kedua (IK-T2) Maqashid Shariah adalah mengamankan diri Manusia.}

Pada tujuan yang kedua yaitu mengamankan diri manusia, tujuan pokok kedua ini terbagi atas dua elemen yaitu: diri sendiri dan kecerdasan. Pada elemen diri sendiri akan terhat bagaimana kontribusi perbankan syariah dalam investasi yang tidak hanya pada sektor keuangan namun juga pada sektor riil. Investasi pada sektor riil dapat dilihat pada investasi perbankan syariah di sektor pertanian, perikanan, pertambangan, dan sektor lainnya yang dapat membantu masyarakat dalam menjalankan usahanya. Jumlah pembiayaan pada sektor riil juga dapat dipengaruhi oleh kondisi ekonomi dan geografis. ada elemen kecerdasan terlihat sebeberapa besar kepedulian bank syariah dalam bidang pendidikan dan pelatihan baik kepada karyawan maupun lingkungan. Aktivitas publikasi dimaksudkan sebagai media sosialisasi dan meningkatkan kesadaran masyarakat terhadap kehadiran perbankan syariah. Pencapaian nilai kinerja (performance) MSI untuk tujuan pokok pertama (IK-T1) antara tahun 2014-2018 mencapai 3.09\% menunjukan kontribusi BSMI dalam menjalankan kegiatan dalam rangka mengamankan diri manusia melalui peningkatan aktualisasi diri sendiri melalui hibah pendidikan melampaui dana pendidikan terhadap karyawan Dalam hal meningkatkan minat masyarakat terhadap eksistensi dari bank syariah, menunjukkan bahwa bank syariah juga telah mengajak manusia untuk berubah menuju kearah yang lebih baik, yaitu dengan menggunakan jasa dari perbankkan Syariah. Indikator Kinerja Tujuan ketiga (IK-T3)
Maqashid Shariah adalah memelihara
masyarakat.
Tujuan ketiga Maqashid Shariah adalah memelihara masyarakat terbagi atas dua elemen yaitu keturunan dan entitas sosial. Indikator ketiga menggunakan Rasio Islamic Quantitative Index Equitable Distribution untuk mengukur kontribusi pada elemen keturunan dengan menganalisa Tujuan ketiga Maqashid Shariah adalah memelihara masyarakat terbagi atas dua elemen yaitu keturunan dan entitas sosial. Indikator ketiga menggunakan Rasio Islamic Quantitative Index Equitable Distribution untuk mengukur kontribusi pada elemenketurunan dengan menganalisa kewajiban perusahaan dalam mensejahterakan masyarakat, karyawan, dan pemegang saham, dengan maksud agar kesejahteraan dari keturunannya pun terjamin. Elemen entitas sosial, dibagi atas beberapa dimensi yaitu pembagian kembali pendapatan dan harta, pembangunan dan sosial, serta indikator sosial. Untuk elemen entitas sosial BMSI mendapatkan nilai tertinggi yaitu sebesar 13,72\% pada tahun 2015 .

Indikator Kinerja Tujuan keempat (IK-T4)
Maqashid Shariah adalah memelihara
lingkungan.
Untuk tujuan keempat yaitu memelihara lingkungan terbagi atas dua elemen yaitu harta dan lingkungan. Pada elemen harta, terbagi atas 
enam dimensi yang mencakup beberapa aspek keuangan untuk mengukur tingkat kesehatan perbankan syariah menggunakan CAMELS terdiri atas : pengembalian yang adil, kecukupan modal, kualitas aset, kualitas manajemen, kemampuan pendapatan, dan likuiditas. Pengukuran kinerja (performance) MSI BMSI sejak tahun 2014-2018 mengalami peningkatan cukup signifikan dari $3 . .01 \%$ pada tahun 2014 hingga $15.15 \%$ pada tahun 2018 .

Pada elemen kedua mengungkap pengukuran indikator perlindungan lingkungan dan donasi ekologi untuk lingkungan. Salah satu komitmen perbankan syariah sesuai dengan prinsip kerjanya adalah menjadi agen kemaslahatan sesuai konsep syariah enterprise theory termasuk tanggung jawab terhadap lingkungan melalui program Corporate Sosial Responsibility (CSR) yang rutin disampaikan pada tahunan. Nilai indikator kinerja (performance) MSI untuk elemen harta tertinggi pada tahun 2015 sebesar $4.20 \%$ sedangkan elemen ekologi pencapaian tertinggi diperoleh pada tahun 2017 sebesar $9.98 \%$.

\section{Kesimpulan, Keterbatasan Dan Implikasi Hasil Penelitian}

Secara keseluruhan hasil analisis menunjukan bahwa kinerja (performance) MSI BMSI baik menggunakan model pengukuran Abu Zahrah maupun model AM Najjar tidak terdapat perbedaan yang terlalu signifikan. Skor kinerja (performance) MSI Abu Zahrah BMSI untuk tahun 2014 -2018 rata-rata menunjukan nilai sebesar adalah $35.65 \%$. Skor kinerja (performance) MSI AM Najjar BMSI untuk tahun 2014 -2018 rata-rata menunjukan nilai sebesar adalah $30.56 \%$. Perbedaan metode pengukuran keduanya terletak pada model pengungkapan elemen-elemen rasio pengukuran dan bobot yang digunakan.Model pengukuran kinerja kinerja (performance) MSI Abu Zahrah menggunakan rasio keuangan (kuantitatif), sedangkan kinerja (per-formance) MSI AM Najjar tidak hanya mengukur kiner-ja (performance) MSI berdasarkan rasio keuangan kuantitatif), semata namun memasukan pula model pengukuran melalui penyataan (kualitatif).

Hingga tahun 2019 hanya terdapat 3 bank syariah yang terdaftar pada bursa efek Indonesi (BEI) dari total 14 Bank Syariah di Indonesia, yaitu: BRI Sya-riah (BRIs), BTPN Syariah (BTPNs), dan Panin Dubai Syaiah Indonesia (BPDs). Penilaian Kinerja (perfor-mance) MSI merupakan evaluasi terhadap kinerja perbankan syariah yang terlihat seperti memiliki semangat yang kuat namun kurang tenaga. Para peng-giat Bank Syariah harus bekerja lebih keras dan lebih serius berbenah jika ingin memenangkan persaingan pasar yang semakin kompetitif. Menimbang citra dan positioning bank syariah yang lebih dari sekedar bank yang beroperasi dengan prinsip keadilan, kejujuran, transparansi, serta bebas dari riba, gharar (penipuan), maysir (spekulasi), dan hal-hal lain yang tidak sesuai syariah tidak selayaknya laju bank syariah seakan jalan ditempat.

Sebagian masyarakat bisa jadi ragu-ragu dan masih memiliki persepsi bahwa antara bank syariah dengan bank konvensional didalam prakteknya ku-rang lebih sama hanya berbeda dalam istilah dan akad semata. Sebab lainnya masyarakat umumnya telah terbiasa menggunakan sistem perbankan konvension-al yang relative masih unggul dari sisi pengembalian (return), kemudahan fasilitas, teknologi informasi, akses, jaringan, dengan konsep layanan pri-ma.Mengamati popupasi muslim yang merupakan mayoritas penduduk Indonesia bahkan di dunia sudah seharusnya bank syariah mampu meyakinkan pasar untuk menjadikan bank syariah sebagai pilihan utama dalam berinvestasi. Pengungka-pan dan pengukuran kinerja (performance) MSI diharapkan mampu memberikan gambaran yang kom-prehensif, lebih luas, dan lebih efektif kinerja perbankan sehingga bank syariah seharusnya merupa-kan solusi dan bukan sebagai alternatif.

\section{Daftar Pustaka}

Antonio, M. S., Sanrego, Y. D., \& Taufiq, M. (2012). An analysis of Islamic banking performance: Maqashid index implementation in Indonesia and Jordania. Journal of Islamic Finance, 176(813), 1-18.

Arikunto, S. (2010). Prosedur Penelitian Suatu Pendekatan Praktik (14 ed.). Jakarta: PT Rineka Cipta.Bank Indonesia. (2009). Peraturan Bank Indonesia. Retrieved from http://www.albayan.ae.

Freeman, R. E., Harrison, J. S., Wicks, A. C., Parmar, B., \& de Colle, S. (2010). Stakeholder theory: The state of the art. Stakeholder Theory: The State of the Art,4(1),1-343. https://doi.org/10.1017/CBO9780511815768. 
Ghozali, I. (2012). Aplikasi Analisis Multivariate Dengan Program SPSS 20. Semarang: Badan Penerbit Universitas Diponegoro.

Hameed, S., Wirman, A., \& Nazli, M. (2004). Alternative Disclosure \& Performance Measures for Islamic Banks. Departement Of Accounting International Islamic University Malaysia, Kuala Lumpur, (June 2016), 1-26.

Bedoui, H. E. (2016). Shari'a-based ethical performance measurement framework, (January 2012). https://doi.org/10.13140/RG.2.2.18433.66401.

J Jensen, M. C., \& Meckling, W. H. (1976). Theory of the firm: Managerial behavior, agency costs and ownership structure. Journal of financial economics, 3(4), 305-360.

Mohammed, M. O., Razak, D. A., \& Taib, F. M. (2008, June). The performance measures of Islamic banking based on the Maqasid framework. In Paper of IIUM International Accounting Conference (INTAC IV) held at Putra Jaya Marroitt (pp. 1-17).

Hartono, N. (2018). Analisis Pengaruh Islamic Corporate Governance (ICG) Dan Intellectual Capital (IC) Terhadap Maqashid Syariah Indeks (MSI) Pada Perbankan Syariah Di Indonesia. Al-Amwal: Jurnal Ekonomi dan Perbankan Syari'ah, 10(2), 259-282.
Mutia, E., \& Musfirah, N. (2017). Pendekatan Maqashid Shariah Index Sebagai Pengukuran Kinerja Perbankan Syariah di Asia Tenggara. Jurnal Akuntansi dan Keuangan Indonesia, 14(2), 181-201.

Keuangan, O. J. (2008). Undang-Undang Republik Indonesia Nomor 21 Tahun 2008 Tentang Perbankan Syariah.

Raharjo, E. (2007). Agency Theory and Stewardship Theory in the Accounting Perspective. Economic Focus, 2(1),37-46. https://doi.org/http://dx.doi.org/10.1016/S0076 $-6879(07) 33002-4$.

Triyuwono, I. S. (2001). Metafora Zakat dan Shari'ah Enterprise Theory sebagai Konsep Dasar dalam Membentuk Akuntansi Syari'ah. Indonesian Journal of Accounting and Auditing, 5(2), 131-145.

Umar H. (2007). Metode Penelitian Untuk Skripsi Dan Tesis Bisnis. Jakarta: PT. Raja Grafindo Persada. 
Rudi Setiyobono, Nurmala Ahmar, Darmansyah: Pengukuran Kinerja Perbankan Syariah Berbasis Maqashid Syariah Index Bank Syariah di Indonesia: Abdul Majid Najjar Versus Abu Zahrah 